\title{
JABAT TANGAN DENGAN CIUM TANGAN KYAI UNTUK KEBERKAHAN DALAM PERSPEKTIF QURAN
}

\author{
Tammulis 1*), M. Galib M 2), Achmad Abubakar 3) \\ 1)Pascasarjana UIN Alauddin Makassar, 2,3)UIN Alauddin Makassar \\ 1)intankmuhlis@gmail.com, 2)Muhammad.galib@yahoo.com, 3)achmad.abubakar@uin- \\ alauddin.ac.id \\ *Penulis koresponden

\begin{tabular}{|l|l|l|}
\hline Diajukan: 04-06-2021 & Diterima: 09-06-2021 & Diterbitkan: 12-06-2021
\end{tabular}

\begin{abstract}
This research is related to the source of the Quran regarding the culture of students who kiss the hands of clerics or scholars with the belief to get blessings (tabarruk). The are two formulations of the problem, namely what is the view of the Quran regarding the culture of shaking hands by kissing the hands of scholars or kyai? Can kissing the hands of scholars or kyai get blessings according to the Quran? This study uses verse analysis and interpretation of the Quran with the maudū'ìy (thematic) interpretation method. As for the conclusion that kissing the hands of a cleric or cleric as a form is permissible in the Qur'an, even the Quran obliges to glorify the ulama. The handshake by kissing the cleric's hand, according to the Quran, can invite blessings from Allah because in the Quran one of the things that causes blessings to come down for people who always greet and stay in touch. Even in the Qur'an it is stated that then ulama are those who fear Allah, and those who are pious according to the Quran will be blessed by Allah SWT.
\end{abstract}

Keywords: shake hand, kiss the kyai hand, blessing

\begin{abstract}
Abstrak: Penelitian ini difokuskan pada sumber Quran mengenai budaya santri yang mencium tangan kiyai atau ulama dengan keyakinan untuk mendapatkan berkah (tabarruk). Rumusan masalah ada dua yaitu bagaimana pandangan Quran mengenai budaya jabat tangan dengan mencium tangan ulama atau kyai? Apakah mencium tangan ulama atau kyai bisa mendapat keberkahan menurut Quran? Penelitian ini menggunakan analisis ayat dan tafsir Quran dengan metode tafsir mauḍūîy (tematik). Adapun kesimpulan bahwa mencium tangan kiyai atau ulama sebagai bentuk penghormatan itu dibolehkan dalam Quran, bahkan Quran mewajibkan untuk memuliakan ulama. Adapun salaman dengan mencium tangan kyai hal itu bisa mengundang turunnya berkah dari Allah karena salah satu yang menyebabkan turunnya berkah bagi orang yang selalu memberi salam dan bersilaturrahmi. Bahkan dalam Quran disebutkan bahwa ulama itulah orang yang bertaqwa kepada Allah, dan kepada orang orang yang bertaqwa akan diberkahi oleh Allah SWT.

Kata kunci: Berjabat Tangan, Cium Tangan Kyai, Keberkahan
\end{abstract}




\section{A. Pendahuluan}

Quran merupakan kitab suci yang diturunkan Allah kepada hambanya untuk menjadi petunjuk bagi manusia dalam mencapai kebahagian dan keselamatan dunia dan akhirat, Quran berlaku sampai akhir zaman artinya petunjuk petunjuk dalam Quran selalu sesuai dengan perkembangan zaman. Quran yang dibaca dan dipakai pada zaman Nabi Muhammad saw tidak sedikitpun berbeda dengan yang kita pakai saat ini, jangankan satu ayat atau satu kata, satu huruf pun tidak ada yang berbeda. Dan Quran akan selalu terpelihara keasliannya karena hal itu merupakan janji Allah dalam Quran, sebagaimana firman Allah dalam Quran, surah al-Hijr (15): 9; “Sesungguhnya kami yang menurunkan adz-dzikr, dan sesungguhnya kami benar benar baginya adalah pemelihara." ${ }^{1}$

Dalam ayat tersebut, Allah SWT menyebutkan bahwa dia terlibat langsung dalam pemeliharaan Quran, sehingga akan langgeng tanpa perubahan sedikitpun. ${ }^{2}$ Akan tetapi penafsiran atas teks Quran akan sangat mungkin berubah-rubah karena perbedaan konteks serta metode yang digunakan sebagai pisau analisis tafsir, oleh sebab itu AlQurean selalu terbuka untuk dianalisis, dipersepsikan dan ditafsirkan dengan berbagai metode dan pendekatan yang berbeda-beda dalam rangka menyingkap makna dan pesan yang tersimpan di dalamnya. Kandungan Quran yang begitu luas tentunya memberi ruang tafsir yang luas pula. Karena memang Quran dapat diibaratkan sebuah permata yang semua sisinya memancarkan sinar sehingga setiap orang atau kelompok selalu mendasarkan argumen dan pandangannya kepada Quran, kendati pandangan mereka saling berseberangan. ${ }^{3}$

Dalam tradisi pemikiran Islam, menafsirkan Quran sebagai upaya memahami pesan-pesan Tuhan sering dipahami sebagai tugas yang tak pernah mengenal kata berhenti. ${ }^{4}$ Tugas tersebut senantiasa harus selalu

${ }^{1}$ M. Quraish Shihab, Tafsir Al-Mishbah: Pesan, Kesan dan Keserasian Al-Qur'an (Jakarta: Lentera Hati, 2002), IV: 420.

${ }^{2}$ Shihab, Tafsir.

3 M. Nur Kholis Setiawan, Quran Kitab Sastra Terbesar (Yogyakarta: elSAQ Press, 2005), 1.

4 Nasaruddin Umar, Deradikalisasi Pemahaman Quran dan Hadis (Jakarta: PT. Elex Media Komputindo, 2014), 1. 
dilakukan kapan pun dan di mana pun sesuai dengan perkembangan situasi dan kondisi sosial yang ada. Artinya Quran harus senantiasa ditafsirkan untuk menjadi landasan teologis bagi setiap pemecahan persoalan aktual yang muncul ke permukaan. Quran juga harus senantiasa ditafsirkan untuk mengesahkan dan menjadi standar kebenaran untuk semua tingkah laku manusia, menyemangati berbagai perjuangan, melandasi berbagai aspirasi, memenuhi berbagai harapan, melestarikan berbagai kepercayaan dan memperteguh jati diri penganutnya. ${ }^{5}$

Sehubungan dengan hal tersebut di atas, ada sebuah tradisi/ budaya terutama dikalangan para santri di pesantren, ketika berjabat tangan dengan kiyai atau ustadz, mereka mencium tangan, sebagai suatu bentuk tabarruk dan ta'dzim. hal itu banyak menjadi sorotan dari beberapa pihak termasuk dari orang orang yang paham agama yang menganggap hal itu tidak ada dasarnya bahkan dianggap suatu bentuk pengkultusan atau perbuatan syirik.

Hal ini melatar belakangi sehingga penulis mencoba untuk meneliti mengenai tradisi atau budaya jabat tangan dan mencium tangan ustadz atau ulama untuk mendapatkan keberkahan dalam perspektif Quran. Batasan masalah pada; 1) Bagaimana pandangan Quran mengenai budaya jabat tangan dengan mencium tangan kiyai/ ulama? 2) Apakah dengan mencium tangan ulama/ kiyai bisa mendapatkan keberkahan menurut Quran?

Berdasarkan penelusuran beberapa artikel maka ditemukan beberapa artikel yang terkait dengan pembahasan ini diantaranya “Tabarruk dan Berkah dalam Berbagai Perspektif.”6 Artikel ini memuat berbagai pandangan tentang barakah dan tabarruk dalam perspektif Quran dan Hadits, pandangan ulama al-salaf al-salih, dan juga di kalangan masyarakat pesantren, terutama yang tradisional. Dalam pembahasan artikel ini, hanya membahas secara umum berkah dalam

5 Mohammad Arkoun, Kajian Kontemporer Al-Qur'an, trans. Hidayatullah (Bandung: Pustaka, 1988), 1; Firdaus et al., "Various Methods of Establishing Contemporary Islamic Law," Ulumuddin: Jurnal Ilmu-ilmu Keislaman 10, no. 1 (2020): 39-58.

6 Fera Andriani, “Tabarruk dan Barakah dalam Berbagai Perspektif," Syaikhuna: Jurnal Pendidikan dan Pranata Islam 11, no. 2 (Oktober 19, 2020): 243-260. 
perspektif Quran sementara dalam artikel yang kami buat ini kajiannya secara khusus pada ayat ayat Quran dan dikhususkan pada satu model tabarruk yaitu cium tangan ulama. Artikel yang lain yang ditemukan yaitu "Membaca Fenomena Ziarah Wali di Indonesia: Memahami tradisi tabarruk dan Tawassul."7 dalam artikel ini membahas tabarruk dengan menziarahi kuburan para ulama atau wali sementara dalam artikel yang kami tulis ini, bentuk tabarruk-nya dengan mencium tangan ulama.

\section{B. Metode}

Penelitian ini menggunakan penelitian kualitatif yang berbentuk library research (penelitian Pustaka). Jenis penelitiannya adalah deskriptif verifikatif. Penelitian ini dilaksanakan untuk menggambarkan dan menjelaskan konsep Alquran tentang tabarruk dengan mencium tangan ulama/kiyai dengan menggunakan pendekatan ilmu tafsir. Pendekatan ilmu tafsir disini adalah pendekatan yang menggunakan beberapa kitab tafsir dalam mendeskripsikan dan menganalisis data ayat. Kemudian, metode yang digunakan adalah metode atau cara kerja tafsir mauḍū'ìy (tematik). Perluasan tema dimungkinkan dengan bidang kemasyarakatan temporer yang belum terjamah oleh penafsir salaf secara langsung. Hal demikian juga dilakukan oleh Nugroho, ${ }^{8}$ Uyuni, ${ }^{9}$ dan Ridho dkk. ${ }^{10}$ Sumber data kemudian yaitu Quran sebagai sumber data primer, namun untuk keperluan analisis guna menginterpretasi data primer, maka dibutuhkan data skunder diantaranya: Kitab-kitab tafsir dan hadis yang relevan dengan permasalahan, buku buku yang relevan serta ensinklopedia dan kamus seperti al-Mu’jam al-Mufahras li Alfāẓ al-Qur’ān al-Karīm karya Muhammad Fuād Abd al-Bāqī dan lainnya.

7 Asmaran Asmaran, "Membaca Fenomena Ziarah Wali Di Indonesia: Memahami Tradisi Tabarruk Dan Tawassul," Al-Banjari : Jurnal Ilmiah Ilmu-Ilmu Keislaman 17, no. 2 (Desember 31, 2018): 173-200.

8 Taufik Nugroho, "Pendidikan Karakter Dalam Al-Qur'an (Studi Tafsir Pendidikan Surat Luqman)," Ulumuddin Jurnal Ilmu-ilmu Keislaman 4, no. 1 (2014): 14-22.

9 Yuyun Rohmatul Uyuni, "Konsep Pola Asuh Orang Tua Dalam Perspektif Islam Terhadap Tumbuh Kembang Anak Dalam Keluarga," aș-șibyān: Jurnal Pendidikan Anak Usia Dini 4, no. 1 (2019): 53-64.

10 Muhammad Ridho Hisyam et al., "Peran Anggota Keluarga Berketahanan Dalam Perspektif Quran,” Ulumuddin: Jurnal Ilmu-ilmu Keislaman 9, no. 2 (2019): 171186. 


\section{Deskripsi dan Pembahasan}

Bagaimana Pandangan Quran Tentang Jabat Tangan dengan Mencium Tangan

Mengenai hukum jabat tangan dengan mencium tangan tidak ditemukan langsung term-nya dalam Quran namun ada beberapa ayat yang terkait dengan hal itu yang bisa dijadikan objek kajian, diantaranya QS. al-Baqarah (2): 34; "Dan (Renungkan pula) ketika kami berfirman kepada para malaikat, sujudlah kepada Adam, maka merekapun segera sujud. Tetapi Iblis enggan sujud dan angkuh. Dan dia termasuk kelompok yang kafir." 11

Dalam ayat ini berisi tentang perintah Allah kepada malaikatnya untuk bersujud kepada Nabi Adam as, dimana pada ayat sebelumnya Allah menceritakan bagaimana Adam akan dijadikan sebagai khalifah dan diberikan kelebihan berupa ilmu (wa a'llama aadama asmaa a kullahaa) kemudian Allah perintahkan para malaikat untuk bersujud kepada Adam 12 سجود تحية as., dalam tafsir jalalain makna sujud disini diartikan sebagai بالانحناء (sujud penghormatan dengan membungkuk atau menundukkan kepala ) dalam tafsir Ibn Katsir juga disebutkan bahwa pendapat yang lebih kuat yang menyebutkan bahwa sujud kepada Adam adalah penghormatan, salam serta memuliakannya. ${ }^{13}$ Bahkan Shihab dalam tafsir al-Misbah mengatakan bahwa ayat ini dapat menjadi dasar tentang kewajiban menghormati orang orang yang berpengetahuan. ${ }^{14}$

Melihat penjelasan di atas kita dapat memahami bahwa Quran mewajibkan kita untuk menghormati dan memuliakan orang orang yang berilmu bahkan perhormatan itu dilakukan dalam bentuk perintah sujudnya malaikat kepada Adam as, jika kita Qiaskan dengan salaman sambil mencium tangan para kiyai atau ustadz dalam bentuk memuliakan

${ }^{11}$ Shihab, Tafsir, I: 83.

12 Al- Mahally Jalaluddin Muhammad ibn Ahmad dan al-Suyuthy Jalaluddin abdu ar-Rahman ibn Abi bakr, Tafsir al Jalalain (Surabaya: Nurul Huda, n.d.), 6.

${ }_{13}$ Ismail Abu al-Fida Ibn Umar Ibn Katsir Ad-Dimasyqiy, Tafsir Quran al-Azim (Beirut: Dar al-Kutub al-Ilmiyah, 1997), I: 139.

${ }_{14}$ Shihab, Tafsir, I: 139. 
atau menghormati orang berilmu maka tentu hal itu tidak bertentangan dengan Quran. Hal ini dikuatkan dengan hadis Rasulullah saw.; ${ }^{15}$

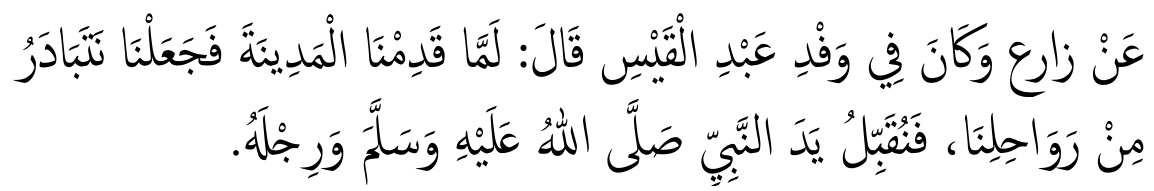

"Dari Zarra' dia termasuk utusan Abdu Qais berkata: "Ketika kami sampai ke Madinah, kami bergegas turun dari kendaraan kami lalu kami mencium tangan dan kaki Nabi Muhammad Shallallah alihi wa sallam..."

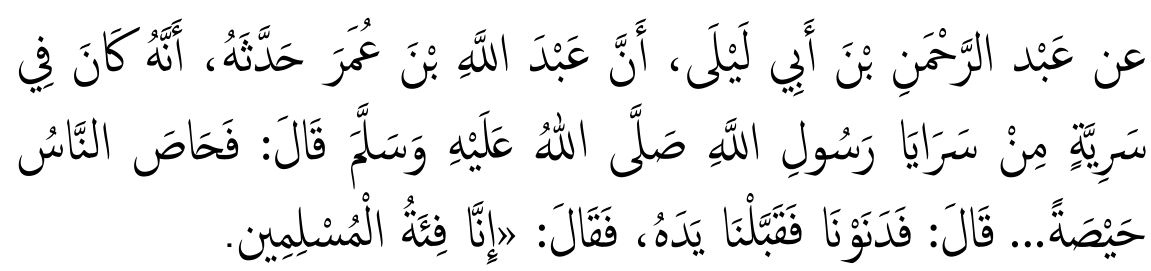

"Bahwasanya Abdullah bin 'Umar bercerita kalau ia pernah berada di sebuah rombongan pasukan pengintai (sariyyah) Rasulullah Saw. Kemudian, pasukan melarikan diri dan saya termasuk di antaranya... Ibn 'Umar berkata: "Kami kemudian mendekati Nabi dan mencium tangannya". Nabi Saw. merespon dengan mengatakan: "saya adalah bagian dari umat muslim."16

Berkah Dalam Quran

Kata barakaat merupakan bentuk jamak dari barakah, barakah itu merukan isim Masdar dari baraka. Kata yang berasal dari tiga huruf ini( ba ro dan kaf) dengan segala perubahannya berulang sebanyak 31 kali dalam Quran. Dalam 9 bentuk, ${ }^{17}$ yaitu: 1) Baaraka pada QS.al-Fussilat (41): 10; 2) Buurika di QS. An-Naml (27): 8; Tabaarak di QS. AL-A'raf (7): 54, QS. Al-Mu'minun (23): 14, QS. Al- Furqan (25): 1,10, 61, QS. ALMu'min (40): 64, QS. AS- Zukhruf (43): 85, QS. Al-Rahman (55): 7, QS. AL-Mulk (67): 1; Barakaatin di QS. AL-A'raf (7): 96, Qs. Hud (11) :48; Mubaarak di QS. AL-An'am (6) :92,155, QS. AL-Anbiya (21):50, QS. Shadd (38) :29; Mubaarakah di QS. An-Nur (24) :35, 61, QS. AL-Qashash (28):30, QS. ad-Dukhaan (44):3; Baaraknaa, QS. AL-A'raf (7): 137, QS. AL-Isra (17) :1, QS. AL-Anbiya (21): 71,81, QS. Saba (34) :18, Mubaarakaa

${ }_{15}$ Abu Daud, Sunan Abi Daud (Jakarta: Maktabah Dahlan, n.d.), IV: 357

16 Ibid., IV:46.

17 Abdul Baqi Muhammad Fuad, Mu’jam al Mufahras lilfazil qur'anil karim (Mesir: Darul Kutub, 1945), 118. 
di QS. Ali Imran (3) : 96, QS. Maryam (19) :31, QS. Al-Mu'minuun (23) :29, QS. Qaaf (50) :9; dan Barakaatuh di QS. Hud (11): 73

Itulah bentuk bentuk kata barakah dalam Quran, namun kami tidak akan membahasa secara keseluruhan dari 31 ayat di atas, kami membatasi hanya membahas 3 ayat yang terkait dengan permasalahan yang kita bahas saat ini yaitu QS. AL-A'raf (7) :96, QS.Hud (11): 48, QS. An-Nur (24):61

Ayat Pertama. QS. Al-A'raf (7): 96

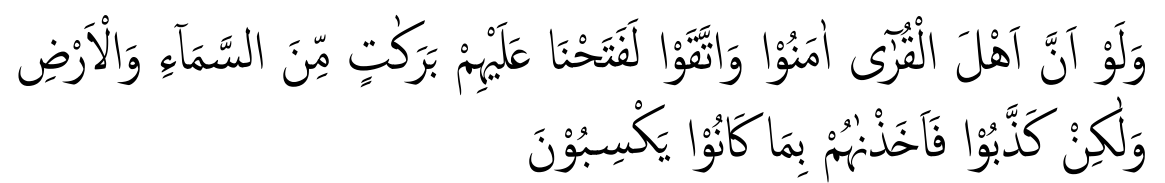

Dan sekiranya penduduk negeri beriman dan bertakwa, pasti Kami akan melimpahkan kepada mereka berkah dari langit dan bumi, tetapi ternyata mereka mendustakan (ayat-ayat Kami), maka Kami siksa mereka sesuai dengan apa yang telah mereka kerjakan. ${ }^{18}$

Didalam ayat di atas jelas bahwa keberkahan bisa diberikan jika seseorang atau kaum beriman dan betaqwa kepada Allah Adapun bentuk keberkahan yang dimaksud dalam ayat tersebut adalah: 1) kebaikan yang banyak yang menghasilkan kesejahtraan lahir batin, ,2) Negeri aman dan sejahterah sebagaimana penduduk Madinah dibawah bimbingan Rasulullah Saw, 3) Selalu merasa aman dan optimis serta mendapat ketenagan batin dalam bekerja dan menerima hasil pekerjaannya, 4)Meraih kenikmatan yang banyak dari alam raya, 5)Keberkahan langit maksudnya keberkahan spiritual sedangkangkan keberkahan bumi yaitu keberkahan materi, 6) Berkah langit adalah hujan, sedangkan berkah bumi adalah tumbuh tumbuhan. ${ }^{19}$

Ayat ke dua yaitu QS. Hud (11): 48

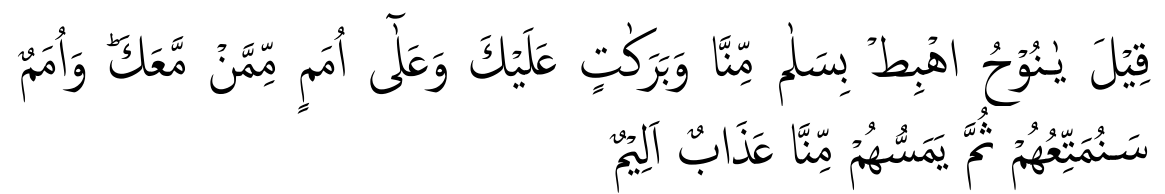

Difirmankan, "Wahai Nuh! Turunlah dengan selamat sejahtera dan penuh keberkahan dari Kami, bagimu dan bagi

18 Lajnah Pentashih Al Qur'an Departemen Agama RI, Al-Quran dan Terjemahannya (Bandung: Syamil Cipta Media, 2002).

19 Shihab, Tafsir, IV: 216-220. 
semua umat (mukmin) yang bersamamu. Dan ada umatumat yang Kami beri kesenangan (dalam kehidupan dunia), kemudian mereka akan ditimpa azab Kami yang pedih."20

Dalam tafsir al-Misbah quraidsh shihab menjelaskan bahwa permohonan ampun dan rahmat nabi nuh as dikabulkan oleh Allah sehingga Allah firmankan kepadanya Hai Nuh turunlah dari bahterah dengan keselamatan yang agung dan anaeka keberkahan yakni kebaikan yang tumbuh berkembang yang bersumber dari kami atasmu dan orang orang yang turun bersamamu serta umat umat yang akan datang sampai hari kiamat. ${ }^{21}$

Dari penjelasan Quraish shihab di atas dapat dipahami bahwa keberkahan akan selalu diberikan kepada semua orang beriman dan orang yang beristigfar terhadap dosa dosanya, bentuk keberkahannya yaitu kebaikan yang tumbuh berkembang Dalam tafsir Jalalain keberkahan yang akan diberikan yaitu kebaikan kebaikan yang akan berlanjut kepada keturunan keturunanya (yang beriman). ${ }^{22}$ Begitu juga yang dijelaskan dalam tafsir ibnu Katsir bahwa Allah menyampaikan kepada Nabi Nuh bahwa ucapan salam yang berisi kesejahtraan dan keberkahan akan diperuntukaan kepada semua orang beriman yang bersamanya dan semua keturunanya sampai hari kiamat. ${ }^{23}$ Artinya semua orang beriman sampai hari kiamat akan diberkahi oleh Allah termasuk orang orang beriman sekarang ini.

Setelah kita baca penjelasan dari berbagai tafsir mengenai QS.Hud 11/48 di atas maka dapat ditarik kesimpulan bahwa keberkahan akan diberikan kepada semua orang beriman dan orang yang senantiasa beristigfar, Adapun bentuk keberkahannya yakni kebaikan yang tumbuh berkembang dari Allah SWT sampai hari kiamat Ayat ketiga: QS. An-Nur (24) : 61

20 Ibid., V: 641.

21 Ibid

22 ibn Abi bakr, Tafsir, 174.

23 Ad-Dimasyqiy, Tafsir, I: 283. 


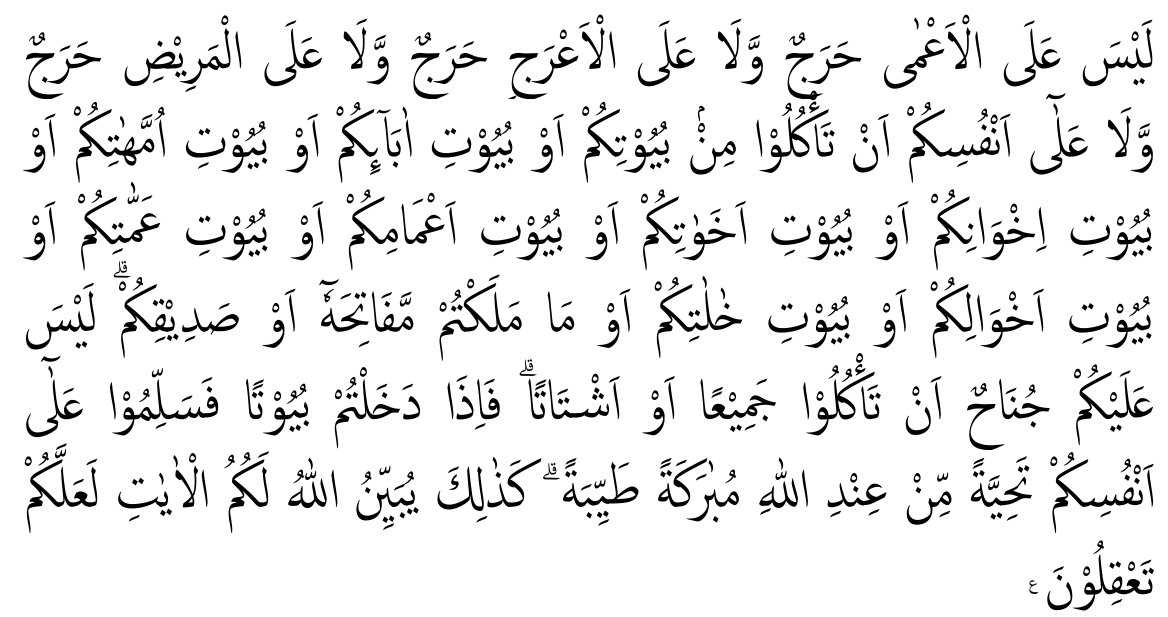

Tidak ada halangan bagi orang buta, tidak (pula) bagi orang pincang, tidak (pula) bagi orang sakit, dan tidak (pula) bagi dirimu, makan (bersama-sama mereka) di rumah kamu atau di rumah bapak-bapakmu, di rumah ibu-ibumu, di rumah saudara-saudaramu yang laki-laki, di rumah saudarasaudaramu yang perempuan, di rumah saudara-saudara bapakmu yang laki-laki, di rumah saudara-saudara bapakmu yang perempuan, di rumah saudara-saudara ibumu yang laki-laki, di rumah saudara-saudara ibumu yang perempuan, (di rumah) yang kamu miliki kuncinya atau (di rumah) kawan-kawanmu. Tidak ada halangan bagi kamu makan bersama-sama mereka atau sendiri-sendiri. Apabila kamu memasuki rumah-rumah hendaklah kamu memberi salam (kepada penghuninya, yang berarti memberi salam) kepada dirimu sendiri, dengan salam yang penuh berkah dan baik dari sisi Allah. Demikianlah Allah menjelaskan ayat-ayat(Nya) bagimu, agar kamu mengerti. ${ }^{24}$

Dalam ayat tersebut di atas ulama berbeda pendapat mengenai maknanya diantaranya ada yang berpendapat bahwa pada mulanya mereka merasa keberatan makan Bersama orang buta karena orang buta tidak dapat melihat makanan dan lauk pauk yang ada dalam hidangan dan barangkali orang lain (yang tidak buta ) mendahuluinya dalam menyantap hidangan yang disuguhkan. Tidak pula Bersama orang pincang, sebab orang pincang tidak dapat duduk dengan baik sehingga teman-teman seduduknya menjauh darinya. Tidak pula orang-orang sakit sebab orang yang sedang sakit tidak dapat menyantap hidangan dengan sempurna sebagaimana yang lainnya, maka dari itu mereka tidak mau makan Bersama orang-orang tersebut agar mereka tidak berbuat aniaya,

${ }^{24}$ Shihab, Tafsir, VI: 613. 
kemudian Allah SWT menurunkan ayat ini. ${ }^{25}$ Ad-Dahhak mengatakan bahwa dulu sebelum nabi saw diutus mereka merasa keberatan bila makan Bersama orang-orang itu karena mereka merasa jijik dan enggan serta menghindari agar orang-orang itu tidak tersinggung. Kemudian Allah SWT menurunkan ayat ini. ${ }^{26}$

Ada juga yang berpendapat bahwa orang yang memiliki udzur sebgaimana yang disebut dalam ayat itu enggan makan Bersama orang lainsetelah menyadari bahwa ada yang enggan ikut makan Bersama mereka karena jijik dengan yang berpenyakit, merasa rikuh makan dengan yang buta atau kesempitan duduk karena yang pincang. Sehingga ayat ini turun menegur orang yang beruzur itu dan menyatakan bahwa hal itu bukanlah alas an untuk tidak mau makan dengan yang lain atau berkunjung kerumah runah kaum muslimin. ${ }^{27}$ As-saddi mengatakan bahwa seorang yang masuk ke rumah ayahnya atausaudara laki-lakinya atau anak laki-lakinya lalu istri pemilik rumah menyuguhkan makanan kepadanya tapi dia tidak mau makan karena pemilik rumah tidak ada di tempat maka Allah SWT menurunkan ayat ini. ${ }^{28}$

Qatadah mengatakan bahwa Sebagian orang dari Bani Kinanah sejak masa jahiliah menganggap perbuatan yang hina bila seseorang makan sendirian, sehingga seseorang dari mereka terpaksa masih terus menggiring unta gembalaannya dalam keadaan lapar hingga bersua dengan seseorang yang mau makan dan minum bersamanya.Lalu Allah SWT menurunkan firmanNya (sesudah masa Islam), yaitu : Tidak ada halangan bagi kalian makan Bersama-sama mereka atau sendirian.(AnNur ;61)Ini merupakan suatu kemurahan dari Allah SWT yang mengisinkan seseorang makan sendirian atau secara berjamaah, walaupun makan dengan berjamaah lebih berkah dan lebih utama. ${ }^{29}$

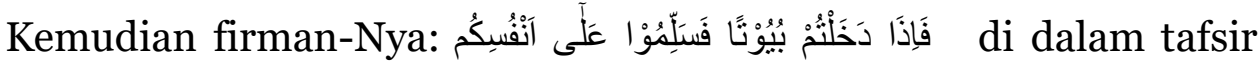
jalalain disebutkan bahwa perintah mengucapkan salam kepada dirinya

${ }_{25}^{25}$ Ad-Dimasyqiy, Tafsir, VI: 78.

26 Ibid.

${ }_{27}^{27}$ Shihab, Tafsir, VI: 813.

${ }_{28}^{2}$ Ad-Dimasyqiy, Tafsir, VI: 78.

29 Ibid., VI: 79. 
sendiri jika kita memasuki rumah yang tidak berpenghuni, namun jika ada penghuninya maka berika salam kepada penghuni rumah.dan penghormatan itu akan Kembali kepada yang memberi salam itu. ${ }^{30}$

Salam yang diberkahi lagi baik مُبرَكَةًَ طَيَيَنة yaitu salam yang diajarkan Allah yaitu asalamu alaikum bukan salam yang seperti yang diucapkan oang jahiliah misalnya dengan mengatakan hayyaka Allah yakni semoga Allah memberimu kehidupan. Shihab melanjutkan, Kata مُبرَكَكًَ mubarakah terambil dari kata (بركة) barkah yang bermakna sesuatu yang mantap juga berarti kebajikan yang melimpah dan beraneka ragam serta bersinambung. Kolam dinamai birkah karena air yang ditampung dalam kolam itu menetap mantap di dalamnya tidak tercecer kemana-mana. Keberkatan Ilahi datang dari arah yang sering kali tidak diduga atau dirasakan secara material dan tidak pula dapat dibatasi atau bahkan diukur. Dari sini, segala penambahan yang tidak terukur oleh indra dinamai berkah. Demikian ar-Raghib al-Ashfahani.

Keterangan Shihab lebih jauh, adanya berkat pada sesuatu berarti adanya kebajikan yang menyertai sesuatu itu, misalnya berkat dalam waktu. Bila ini terjadi, akan banyak kebajikan yang dapat terlaksana pada waktu itu dan yang biasanya tidak dapat menampung sebanyak aktivitas baik itu. Berkat pada makanan adalah cukupnya makanan yang sedikit untuk mengenyangkan orang banyak, yang biasanya tidak cukup untuk orang sebanyak itu.

Sementara bagi shihab, kata ( طيبة) thayyibah terambil dari kata ( طاب ) thaba yang berarti menyenangkan, yakni sesuai dengan keinginan hati dan kecenderungan hati manusia. tentu penghormatan yang disampaikan dengan kata salam itu hal yang menyenangkan dan didambakan setiap orang. ${ }^{31}$ Dengan demikian salam itu akan mendatangkan kedamaian hati dan ketentraman

Jadi berdasarkan penjelasan dari penafsiran QS. An-Nur ayat $61 \mathrm{di}$ atas dapat dipahami bahwa cara mendapatkan keberkahan pada ayat di atas yaitu dengan memberikan penghormatan berupa salam kepada orang

3o ibn Abi bakr, Tafsir, II: 58 .

${ }^{31}$ Shihab, Tafsir, VIII: 617-619. 
lain, dengan ucapan salam itu maka Allah akan memberi keberkahan baik kepada yang mengucapkan maupun kepada yang ditujukan salam itu (yang menjawab salam itu), dalam ayat ini juga dipahami bahwa yang bisa mendapatkan berkah adalah orang yang menyambung silaturahmi, silaturahminya bisa dalam bentuk berkunjung ke rumah keluarga /sahabat, makan bersama atau saling memberi salam.

Adapun bentuk bentuk keberkahan yang disebutkan dalam ayat ini yaitu tambahan kebaikan dan berkesinambungan, mendapat salam dari Allah, semakin eratnya tali silaturahmi atau persahabatan, mendatangkan kasih saying dan ketentraman dan juga mendapat pahala yang besar.

Hubungan Antara Jabat Tangan dengan Mencium Tangan Ulama atau Kiyai dengan Keberkahan

Setelah penulis menganalisis 3 ayat Quran di atas maka penulis menemukan ada beberapa cara untuk mendapatkan keberkahan dari Allah SWT. Dengan keimanan dan ketaqwaan kepada Allah SWT (QS. Al-A'raf :96). Dengan keimanan dan istigfar kepada Allah SWT dalam QS. Hud (11): 48). Dengan memberikan penghormatan berupa salam dan menyambung silaturahmi dalam QS. An-Nur (24): 61)

Jika ketiga hal tersebut dikaitkan dengan jabat tangan dengan mencium tangan ulama/kiyai untuk mendapatkan keberkahan (tabarruk), tentu hal itu sejalan dengan isyarat Quran dengan beberapa alasan. Ulama adalah orang beriman dan bertaqwa kepada Allah dengan rujukan QS. Fatir (35): 28. Thahir ibn Asyur menulis bahwa yang dimaksud ulama adalah orang mengetahui tentang Allah dan syariat, sebesar pengetahuannya tentang itu, maka sebesar itu juga rasa khasyat/ takutnya kepada Allah. Namun ada juga yang berpendapat bahwa ulama itu bukan cuma orang yang berilmu agama atau syariat tapi orang yang memiliki pengetahuan tentang fenomena alam dan social dianamai juga dinamai ulama jika pengetahuannya itu menghasilkan khasyat/ takut. ${ }^{32}$

Jadi kita bisa pahami bahwa para ulama yang mengamalkan ilmunya itu adalah orang yang beriman dan bertaqwa kepada Allah,

32 Ibid., XI: 59-62. 
sedangkan dalam QS. Al-A'raf di atas telah dijelaskan bahwa yang bisa mendapatkan berkah dari Allah adalah orang beriman dan bertaqwa. Para ulama itu adalah orang yang selalu mendapat keberkahan dari Allah, ucapannya akan berkah, ilmu berkah, doa doanya berkah. Berjabat tangan dengan cium tangannya sebagai bentuk penghormatan kepadanya bisa mendapat keberkahan berupa ilmu atau minimal kita mendapat doa dari mereka, sebagaimana pengalaman penulis setiap jabat tangan dan mencium tangan para guru dan kiyai di pesantren dulu, selalu mendengar بارك الله للك doa doa dari kiyai diantaranya doanya yang bisa saya dengar (semoga Allah memberkahimu)

Alasan kedua berupa bentuk silaturahmi apalagi kalau salamannya bukan hanya berjabat tangan tetapi juga sambil mencium tangan tentunya hal itu lebih mempererat hubungan emosional dan kedekatan batin kedua orang yang berjabat tangan itu. Pada QS. An-Nur (24): 61 telah diutarakan bahwa salah satu sebab Allah menurunkan berkahnya kepada hambanya jika hambanya memberi salam dan bersilaturahmi. lebih lebih lagi kalau silaturahmi itu dilakukan kepada ulama yang memang orang yang diberkahi oleh Allah.

\section{Penutup}

Jabat tangan dengan cium tangan para ulama/ kiyai bertujuan penghormatan atau memuliakan karena ilmunya sehingga dibolehkan di dalam Quran hal ini didasarkan pada firman Allah dalam QS. al-Baqarah (2): 34 dimana Allah memerintahkan para malaikat sujud kepada nabi Adam karena kelebihan ilmu yang dimiliki Nabi Adam. Ayat ini menjadi dasar tentang kewajiban menghormati orang orang yang berpengetahuan.

Di beberapa ayatnya telah dijelaskan, keberkahan itu bisa turun kepada orang beriman dan bertaqwa, orang yang senantiasa beristigfar, orang yang memberi salam dan menyambung silaturrahmi. Dan menurut QS Fatir (35) :28 orang yang paling bertaqwa kepada Allah adalah ulama, sehingga berjabat tangan sambil mencium tangan para ulama yang merupakan bentuk penghormatan kepada ulama itu juga bentuk menyambung silaturrahmi, apalagi silaturahminya berisi salam dan doa maka tentu perbuatan ini bisa menyebabkan turunnya berkah dari Allah 
SWT. Para generasi selanjutnya disarankan menelusuri makna-makna

Quran memperoleh keberkahan serta ada upaya lebih lanjut meneliti Quran dengan berbagai pendekatan.

\section{Daftar Pustaka}

Ad-Dimasyqiy, Ismail Abu al-Fida Ibn Umar Ibn Katsir. Tafsir Quran alAzim. Beirut: Dar al-Kutub al-Ilmiyah, 1997.

Andriani, Fera. "Tabarruk dan Barakah dalam Berbagai Perspektif." Syaikhuna: Jurnal Pendidikan dan Pranata Islam 11, no. 2 (Oktober 19, 2020): 243-260.

Arkoun, Mohammad. Kajian Kontemporer Al-Qur'an. Diterjemahkan oleh Hidayatullah. Bandung: Pustaka, 1988.

Asmaran, Asmaran. "Membaca Fenomena Ziarah Wali Di Indonesia: Memahami Tradisi Tabarruk Dan Tawassul." Al-Banjari: Jurnal Ilmiah Ilmu-Ilmu Keislaman 17, no. 2 (Desember 31, 2018): 173200.

Daud, Abu. Sunan Abi Daud. Jakarta: Maktabah Dahlan, n.d.

Firdaus, Ahmad Juneidi, Lola Astari, dan Firda Mustikasari. "Various Methods of Establishing Contemporary Islamic Law." Ulumuddin: Jurnal Ilmu-ilmu Keislaman 10, no. 1 (2020): 39-58.

Fuad, Abdul Baqi Muhammad. Mu'jam al Mufahras lilfazil qur'anil karim. Mesir: Darul Kutub, 1945.

Hisyam, Muhammad Ridho, Suyanto, Muhammad Sadzili, Zainul Arifin, dan Ahmad Syafi'i Rahman. "Peran Anggota Keluarga Berketahanan Dalam Perspektif Quran.” Ulumuddin: Jurnal Ilmu-ilmu Keislaman 9, no. 2 (2019): 171-186.

ibn Abi bakr, Al- Mahally Jalaluddin Muhammad ibn Ahmad dan alSuyuthy Jalaluddin abdu ar-Rahman. Tafsir al Jalalain. Surabaya: Nurul Huda, n.d.

Lajnah Pentashih Al Qur'an Departemen Agama RI. Al-Quran dan Terjemahannya. Bandung: Syamil Cipta Media, 2002.

Nugroho, Taufik. "Pendidikan Karakter Dalam Al-Qur'an (Studi Tafsir Pendidikan Surat Luqman)." Ulumuddin Jurnal Ilmu-ilmu Keislaman 4, no. 1 (2014): 14-22.

Setiawan, M. Nur Kholis. Quran Kitab Sastra Terbesar. Yogyakarta: elSAQ Press, 2005.

Shihab, M. Quraish. Tafsir Al-Misbah: Pesan, Kesan dan Keserasian Al Quran. Jakarta: Lentera Hati, 2002.

---. Tafsir Al-Mishbah: Pesan, Kesan dan Keserasian Al-Qur'an. Jakarta: Lentera Hati, 2002.

Umar, Nasaruddin. Deradikalisasi Pemahaman Quran dan Hadis. Jakarta: PT. Elex Media Komputindo, 2014.

Uyuni, Yuyun Rohmatul. "Konsep Pola Asuh Orang Tua Dalam Perspektif Islam Terhadap Tumbuh Kembang Anak Dalam Keluarga.” așșibyān: Jurnal Pendidikan Anak Usia Dini 4, no. 1 (2019): 53-64. 